\title{
O pensamento moral do perdão em crianças ${ }^{1}$
}

\author{
The moral thinking of forgiveness in children
}

\author{
Eloá Losano de Abreu ${ }^{[a]}$, Pollyana de Lucena Moreira ${ }^{[a]}$, Júlio Rique ${ }^{[b]}$ \\ [a] Universidade Federal da Paraíba (UFPB), bolsistas de iniciação científica do CNPq,João Pessoa, PB - Brasil, eloalosano@gmail.com \\ [b] Professor, Mestrado em Psicologia Social da Universidade Federal da Paraíba (UFPB), João Pessoa, PB - Brasil.
}

\section{Resumo}

O presente trabalho teve como objetivo a investigação da qualidade do pensamento do perdão interpessoal e das condições nas quais o perdão é oferecido por crianças. Vinte crianças de 6 a 8 anos de idade responderam a um dilema moral: o Dilema de João, representado em um livro de gravuras seguido de 12 questões semiestruturadas com o objetivo de avaliar a capacidade de role-taking, o entendimento conceitual sobre o perdão e as condições necessárias para que o perdão ocorra. Os resultados mostraram que $100 \%$ das crianças executaram o role-taking, mas apenas 40\% definiram o perdão. O perdão foi visto pelas crianças como estratégia para diminuir a raiva ou como uma consequência natural da diminuição da raiva. Perdoar foi associado ao pedido de desculpas, ao voltar a brincar, ao ato de reparação e à pressão social dos amigos e da religião. As análises indicaram que voltar a brincar e pedir desculpas demonstra uma moral objetiva, com as crianças mostrando na prática a possibilidade de perdoar. Esses resultados iniciais se associam a estudos sobre o julgamento moral e são relevantes para a preparação de currículos de educação moral para o perdão e para o desenvolvimento das pesquisas na área.

Palavras-chave: Perdão interpessoal. Desenvolvimento moral. Cognição social.

\section{Abstract}

This study examined the moral judgment of forgiveness in a sample of 20 children from 6 to 8 years old. Children were interviewed by a moral dilemma that was adapted for the age group. The dilemma was represented in a picture

1 Esta pesquisa foi realizada com o apoio do CNPq e do Ministério da Saúde, por meio de financiamento concedido ao prof. Júlio Rique (Processo 575284\2008-1). 
book, followed by 12 questions presented to evaluate role-taking skills, knowledge of forgiveness and the necessary conditions for forgiving. Findings showed that all children were capable of showing role-taking, but only $40 \%$ of them were able to define forgiveness. Forgiveness was understood as a strategy for anger reduction or as a natural consequence of the diminishing of anger with time. Forgiving was associated with offender's apology, offender's be allowed back to play with friends, and out of reparation and pressure from friends and religion. Analysis showed that offender's apology and offender's been allowed back to play with friends or reconciliation as examples of practical moral judgments based on the concrete operational reasoning of children. Findings were discussed for moral education and the development of the area of research on forgiveness.

Keywords: Interpersonal forgiveness. Moral development. Social cognition.

\section{Introdução}

Na psicologia, uma breve passagem escrita por Piaget ([1932] 1994), no livro O juizo moral da criança, reflete o valor do perdão no desenvolvimento humano. $\mathrm{O}$ conceito de perdão foi apresentado no relato de uma criança ao justificar sua escolha entre formas de justiça por retribuição. Na citada passagem, uma criança de 9 anos (CLA) estava sendo entrevistada com referência a um contexto de violação das regras e punição justa. Perguntou-se a criança: “vale mais punir as crianças ou explicar?". Então, CLA respondeu: "explicar".

O entrevistador voltou a perguntar: "por quê?", e CLA respondeu: "por que assim não fazem mais depois". O entrevistador continuou perguntando: "o que vale mais: explicar e depois punir ou explicar e depois perdoar?". CLA respondeu: "explicar e depois perdoar" (Piaget, [1932] 1994, p. 174).

De acordo com Piaget, a passagem demonstra que as crianças conhecem a noção de perdão como associada a formas mais avançadas do que as sanções por expiação. Com o avanço da idade o pensamento de justiça amadurece em sua forma. Primeiramente, aparecem as sanções expiatórias, que prevalecem até os 7 ou 8 anos. As sanções expiatórias são arbitrárias e não existe relação entre o conteúdo das violações e o castigo recebido. Em seguida, aparecem as sanções por reciprocidade, que se colocam dentro da compreensão de uma justiça por igualdade e prevalece dos 8 até os 11 anos, aproximadamente. Nesse período, verifica-se que, gradativamente, a ênfase na igualdade vai substituindo o respeito unilateral e a obediência à autoridade, que ocorrem na moral heterônoma. As sanções também vão mostrar uma relação de proporcionalidade entre o conteúdo das violações e o castigo aplicado.
Existe uma variedade de sanções por reciprocidade: consequências naturais, compensação, restituição ou equidade. Essa última compreensão surge por volta da pré-adolescência. Existe agora uma noção de justiça por igualdade, que é relativa a condições de necessidade, intenções e méritos, adquirindo uma nova forma, que é a equidade. Ou seja, o julgamento moral começa a considerar os elementos particulares que motivaram a violação.

As observações de Piaget permitem concluir que com a idade, a criança compreende que para suportar a punição expiatória resta adotar uma "atitude estoica" e seguir adiante com suas práticas de violação às regras. $\mathrm{O}$ comportamento não muda e tudo continua na mesma. De modo contrário, a explicação e o perdão podem orientar a criança a deduzir que a violação é um ato de falta de cooperação, reciprocidade e solidariedade, podendo levar a uma modificação do comportamento e, consequentemente, à harmonia social. Manter a harmonia social vai se constituir numa finalidade importante para apoiar o pensamento do perdão.

Apesar dessas colocações, o próprio Piaget ([1932] 1994, p. 175) suspeitava se aos 9 anos de idade o conhecimento do perdão representava uma compreensão real ou se as crianças são "levadas pela dedução a imaginarem uma moral cor-de-rosa em uso no paraíso das crianças ajuizadas". Será que as crianças são capazes de compreender por meio da explicação o perdão em sua forma genuína? Será que o perdão leva uma criança a mudar de comportamento e não reincidir na violação das regras? Essas questões motivam as pesquisas e ainda permanecem em aberto, mas Piaget ajudou a verificar que é a partir da noção de equidade que a moral do perdão começa a despontar como uma possibilidade de resolução de conflitos associada ao pensamento de justiça. 
Mais recentemente, Robert D. Enright e colaboradores elaboraram uma teoria sobre o perdão interpessoal (Enright \& Fitzgibbons, 2000; Enright, Freedman \& Rique, 1998; Enright et al., 1991). Esses autores definiram o perdão interpessoal pela perspectiva da vítima:

Perdoaré uma atitude moral na qual uma pessoa considera abdicar do direito ao ressentimento, julgamentos, afetos e comportamentos negativos para com uma pessoa que a ofendeu injustamente. $\mathrm{E}$ ao mesmo tempo, nutrir a compaixão, a misericórdia e possivelmente o amor para com o outro que ofendeu (Enright, Freedman \& Rique, 1998, p. 46-47).

Enright e colaboradores consideraram o perdão no domínio da moral justificando que perdão só é possível entre pessoas e depende de uma injustiça (a mágoa); para perdoar a pessoa precisa ter um senso de justiça. Por outro lado, Enright et al. (1991) consideraram que para perdoar não é necessário um pedido de desculpas ou mesmo a reconciliação. Segundo os autores, colocar a reconciliação como uma condição para o perdão é aprisionar as vítimas aos seus ofensores - ou seja, quando os ofensores não aceitam mudar seu comportamento injusto, são pessoas estranhas às vítimas, ou já são falecidos, as vítimas ficam sem condições para oferecer o perdão. Em acordo com os autores, Yandell (1998) esclareceu que enquanto a reconciliação não deve ser uma condição para o perdão, o perdão deve ser uma condição para a reconciliação.

Com o intuito de verificar e expandir os estudos sobre as relações entre as noções de justiça e o pensamento sobre o perdão, Enright, Santos e Al-Mabuk (1989) entrevistaram 119 adolescentes e jovens adultos sobre as condições nas quais o perdão interpessoal poderia ser oferecido. Para tanto, os autores adaptaram o Dilema de Heinz e o Dilema do Prisioneiro Foragido utilizados por Kohlberg (1984) para avaliar o pensamento moral de justiça. No pensamento moral de justiça, o dilema se expressa pela questão do dever. O que deve o protagonista da estória fazer para solucionar o conflito? Deve Heinz roubar o medicamento que pode salvar a vida de sua esposa? - Dilema de Heinz; deve o vizinho entregar o prisioneiro foragido a polícia? - Dilema do Prisioneiro Foragido. Porém, para Enright et al. (1991), o perdão não é uma obrigação moral como é a justiça. Perdoar é um ato de compaixão que vai além do pensamento de justiça. Portanto, o dilema moral se expressa de outra forma. Ou seja, interessa conhecer quais as condições pelas quais uma pessoa ofendida injustamente poderia conceber e conceder o perdão. Nesse sentido, a questão é: sobre quais condições Heinz poderia perdoar o farmacêutico que se recusou a vender o medicamento que poderia ter salvado sua esposa (Dilema de Heinz para o Perdão) e sobre quais condições o prisioneiro foragido poderia perdoar o seu vizinho que lhe entregou a policia (Dilema do Prisioneiro Foragido para o Perdão)? Assim, alterando o fim de cada dilema para colocar na situação do perdão, os resultados encontrados levaram à construção de um modelo cognitivo-social de desenvolvimento, que apresenta as diferentes formas de pensamento sobre o perdão.

Nos estudos de Enright, Santos e Al-Mabuk (1989), o perdão foi relacionado à justiça e concebido como:

- vingança/retribuição: o perdão ocorre quando o agente da mágoa sofre uma dor de mesma intensidade daquela sofrida pela vítima;

- restituição ou compensação: o perdão ocorre quando a vítima recebe algo de igual ou maior valor ao que foi perdido;

- pressão social: o perdão ocorre quando a vítima recebe aprovação dos amigos ou dos familiares;

- pressão institucional: o perdão ocorre quando a vítima segue crenças e princípios morais religiosos;

- restauração da harmonia no grupo social. O perdão é oferecido em nome da harmonia social;

- perdão incondicional. O perdão é oferecido como compaixão.

As análises desses pensamentos dos jovens indicaram que as duas primeiras formas estão mais relacionadas à justiça expiatória (ou vingança). Em seguida, ocorre uma orientação heterônoma pelas expectativas sociais e institucionais, demonstrando uma obediência externa e uma busca de aprovação de grupos específicos. Porém, esse pensamento já se refere ao ideal de harmonia social por igualdade e indica um entendimento diferente da posição ocupada pelas vítimas e ofensores na sociedade. Por 
último, surge a noção de perdão como compaixão, independentemente da reconciliação e da harmonia social, mostrando uma compreensão do outro como fim e ligada a julgamentos que demonstram equidade. Sendo assim, constata-se que as formas de pensar sobre o perdão, que se relacionam com noções de justiça mais avançadas, seriam a restauração da harmonia social e o perdão como compaixão. Os autores também verificaram que existe uma relação entre a noção de perdão e a idade dos respondentes, na medida em que os pensamentos mais heterônomos são mais presentes nos adolescentes mais jovens e os pensamentos mais avançados se apresentam com maior frequência entre os mais velhos.

No avanço do pensamento moral, o elemento psicológico latente no desenvolvimento desses julgamentos é a capacidade de role-taking social, ou seja, a capacidade de se colocar no lugar do outro e entender que o outro tem pensamentos, desejos e comportamentos diferentes do seu (Piaget, [1932] 1994). Essa capacidade se desenvolve concomitantemente com a redução do egocentrismo emocional e cognitivo da criança. Inicialmente, a criança é um ser centrado em si mesmo, seu desenvolvimento intelectual e emocional é pautado na satisfação de seus desejos, o mundo físico e o mundo social são compreendidos a partir do ponto de vista da criança. Como a criança é o centro das atenções e dos cuidados na família e na escola, o meio ambiente social mantém esse egocentrismo até que, nas relações com os pares, as crianças começam a diferenciar desejos e intenções pessoais dos desejos e intenções dos outros, em um processo de descentração cognitiva e emocional. Consequentemente, essa capacidade vai possibilitar que as crianças elaborem melhores julgamentos sobre as ações e os sentimentos do outro (Selman, 1980; Yeates \& Selman, 1989).

No processo de desenvolvimento do julgamento moral ainda se encontram dois tipos de julgamentos, que variam em sua origem:

- julgamento prático, no qual as crianças se baseiam nas consequências dos atos para avaliar a gravidade da ação;

- julgamento teórico, no qual as crianças consideram as intenções do outro para avaliar as ações cometidas pelo outro (Piaget [1932] 1994; Camino, Camino \& Leyens, 1996);
Camino, Camino \& Leyens (1996) ressaltam que Piaget ([1932] 1994) ainda subdivide o julgamento teórico em:

- uma dimensão objetiva, que se refere a julgamentos egocêntricos, nos quais as crianças não separam os aspectos subjetivos dos concretos em uma ação e não consideram as intenções do ator da ação;

- uma dimensão subjetiva, que diz respeito a um raciocínio descentralizado, considerando a distinção entre os aspectos concretos e os aspectos subjetivos. Compreende os sentimentos e pensamentos do autor de uma ação, julgando a ação a partir das intenções do outro.

Sendo assim, o julgamento prático deve preceder o julgamento teórico e este, por sua vez, se desenvolve de uma dimensão objetiva até uma dimensão subjetiva (Camino, Camino \& Leyens, 1996). Dessa forma, o desenvolvimento moral se divide em duas dimensões distintas: uma moral objetiva, que se refere ao julgamento pelas consequências das ações, e uma moral subjetiva, utilizada em julgamentos por intenções da ação (Piaget [1932] 1994). Acredita-se que a segunda dimensão deve prevalecer nas pessoas com moral autônoma, porém as duas grandes fases da moral nunca deixam de coexistir, alternando-se de acordo com a capacidade de role-taking da criança e dos adultos.

Mais recentemente, outros autores realizaram trabalhos voltados para o perdão, visando ao desenvolvimento da competência social das crianças (Yeates \& Selman, 1989; Denham, Neal, Wilson, Pickering \& Boyatzis, 2005). De acordo com esses autores, o perdão é importante para a cooperação entre crianças, promoção da autoestima e desenvolvimento de habilidades de resolução de conflitos. Os autores distinguem habilidades afetivas e cognitivas, dando maior ênfase aos aspectos afetivos, considerando a empatia afetiva (não o role-taking) como essencial para o processo de perdoar. Para eles, as crianças iniciam a vida social na escola e as relações interpessoais começam a se aperfeiçoar na medida em que elas aprendem a resolver conflitos e a formar vínculos afetivos positivos. Além disso, elas passam a compreender a influência das regras morais no convívio social e aprendem a identificar emoções complexas, como intenções, motivações e vergonha, 
entre outras. Porém, elas ainda não estão em uma fase do desenvolvimento que permita compreender o perdão como uma atitude moral autônoma. As razões que as crianças apresentam para perdoar consideram o sentimento e o comportamento do ofensor após a mágoa e a intencionalidade da mágoa, levando também em consideração o contexto em que a mágoa ocorreu. Para as crianças, é mais fácil perdoar quando o ofensor reconhece seu erro e pede desculpas, ou quando não houve intencionalidade. Ou seja, trata-se de uma moral mais objetiva.

Diferentemente da perspectiva adotada por Enright et al. (1991), que se concentraram nas cognições morais das vitimas sobre o ofensor, Denham et al. (2005) focalizam o comportamento do ofensor e o consequente sentimento das vítimas. Porém, esses autores apontam a importância da socialização na família e na escola para considerar decisões que favoreçam o entendimento da atitude de perdoar.

Ainda, no âmbito da psicologia social contemporânea, a abordagem do perdão desenvolvida por Enright (Enright \& Fitzgibbons, 2000; Enright, Freedman \& Rique, 1998, Enright, Santos \& Al-Mabuk, 1989, Enright, et al., 1991) define a virtude no domínio do pensamento moral das crianças como uma atitude. Nesse sentido, a formação de atitudes sociomorais são vistas pela psicologia social como influenciadas pelo processo de socialização, educação e fatores acidentais determinantes (ex: tipo de educação parental e escolar). Rodrigues (1991, p. 345, grifos nossos) define as atitudes como: "uma organização duradoura de crenças e cognições em geral, dotadas de carga afetiva pró ou contra um objeto social [i.e., perdão] definido, que predispõe a uma ação coerente com as cognições e afetos relativos a este objeto [i.e., perdão]".

As atitudes sociomorais são influenciadas pelas experiências pessoais que geram julgamentos e comportamentos morais sobre o outro (Rodrigues, 1991). No tocante à experiência de uma pessoa que foi vítima de uma injustiça, ele ou ela deve considerar a sua indignação, raiva e ressentimento e responder sobre a situação a partir de sua noção de justiça: vingança, compensação, harmonia social pelo perdão, ou compaixão.

Considerando que as noções de justiça são construídas dependendo da capacidade de role-taking e que as atitudes são influenciadas por fatores como tipo de educação, o perdão tem sido incluído em currículos educacionais como uma alternativa aos programas tradicionais de desenvolvimento moral e promoção da saúde mental. $\mathrm{Na}$ literatura atual se verifica que esses programas são majoritariamente voltados para contextos de mágoas específicas como, por exemplo, crianças e adolescentes vítimas de negligência parental (Al-Mabuk, Enright \& Cardis, 1995), depressão (Reed \& Enright, 2006), entre outros (Wade, Bailey \& Shaffer, 2005; Gambaro, Enright, Baskin \& Klatt, 2008).

Pode-se citar, por exemplo, o estudo de Holter, Magnuson, Knuston, Knuston Enright e Enright (2008) que investigaram os efeitos de um programa de educação para o perdão nos níveis de raiva e depressão em crianças estadunidenses de 5 a 12 anos de idade, estudantes de uma escola pública. As crianças foram divididas em três grupos, com idades médias de 7, 9 e 11 anos, respectivamente. Cada grupo de idade foi dividido em grupo experimental e grupo controle. As atividades com o grupo experimental foram realizadas utilizando do currículo "Jornada para o Perdão (Adventure of Forgiveness)", cujo objetivo era apresentar às crianças os conceitos fundamentais do perdão interpessoal.

As análises de comparação dos grupos no pré-teste e no pós-teste demonstraram que os grupos experimentais das idades de 7 e 11 anos apresentaram diminuição significativa no nível de raiva, comparados com os respectivos grupos controle. No grupo de 9 anos de idade, não houve diferença significativa entre grupo experimental e controle, porém identificou-se diminuição no nível de raiva no grupo como um todo. No tocante ao nível de depressão, nenhum dos grupos de idade apresentou diminuição significativa.

Hepp-Dax (1996), com o objetivo de diminuir a rivalidade por discriminação racial entre alunos de uma escola pública de Nova York, elaborou um currículo a partir da adaptação para crianças do manual de intervenção para o perdão para vitimas de incesto (Freedman \& Enright, 1996) e utilizou este currículo em um programa de intervenção educacional. Ela selecionou 24 crianças, meninos e meninas com idade média de 10 anos, e os dividiu em grupo experimental e grupo controle. No tratamento experimental foi utilizada a intervenção para o perdão, enquanto nas atividades com o grupo controle foram administradas aulas de ecologia. A intervenção foi dividida em duas etapas, de dois meses de duração cada uma. Após os dois primeiros meses de atividades, os grupos passaram por uma medida intermediária e o grupo controle passou a 
receber o tratamento experimental e o grupo experimental, as aulas de ecologia. Após o quarto mês, todos os participantes foram avaliados por um pós-teste. Os resultados da comparação pré e pós-teste indicaram diferenças significativas nas médias de perdão para ambos os grupos que passaram pelo tratamento experimental. Foi realizado ainda um re-teste sete meses após o fim da intervenção e os resultados apontaram que, além do aumento nas médias de perdão, também houve um aumento no nível de autoestima das crianças, demonstrando os efeitos positivos da terapia para o perdão.

Gambaro et al. (2008) analisaram os efeitos do "Aconselhamento para o Perdão" (Forgiveness Couseling - FC) em um grupo de adolescentes com idades entre 12 e 14 anos. A FC é uma abordagem terapêutica voltada para a diminuição da raiva e a restauração da saúde emocional. Estudos foram realizados com crianças utilizando o FC (Enright, Knuston-Enright, Holter, Baskin \& Knuston, 2007, apud Gambaro et al., 2008). Os resultados desses estudos indicaram que as crianças que participaram do Aconselhamento aprenderam sobre o perdão, demonstraram redução no nível de raiva e passaram a utilizar o perdão como estratégia de resolução de conflitos interpessoais, reduzindo então suas emoções negativas. Estudos realizados com adultos apresentam resultados semelhantes, indicando melhoras na saúde emocional. O objetivo do estudo de Gambaro et al. (2008) foi verificar como este tipo de abordagem poderia influenciar as relações interpessoais como um todo, não exclusivamente entre pessoas que se envolveram em conflitos, ou seja, verificar se os efeitos do Aconselhamento para o Perdão se estendiam para todos os âmbitos da vida social. Nesse sentido, eles dividiram jovens adolescentes em dois grupos: um participante das sessões de Aconselhamento e o outro participante de sessões de terapia centrada do cliente (ACP). A escolha dos participantes foi determinada pelos escores obtidos no teste de ansiedade e raiva, nas dificuldades acadêmicas e que tinham alguma experiência de mágoa profunda com outra pessoa. Os resultados demonstraram melhora significativa nos participantes do Aconselhamento, tanto nos escores de raiva e ansiedade como no desempenho geral nas relações interpessoais.

No Brasil, a literatura especializada mostra que ainda não existem estudos sobre o pensamento do perdão em crianças. Essa ausência de estudos aponta para a necessidade de uma intervenção educacional que contemple as exigências da área de desenvolvimento moral do perdão. Em função disso, o presente trabalho tem como objetivo a investigação da qualidade do pensamento do perdão interpessoal e das condições nas quais o perdão é oferecido por alunos de escolas de nível primário do Nordeste brasileiro, como condição inicial para a preparação de currículos de educação moral para o perdão e para o desenvolvimento das pesquisas na área.

\section{Método}

\section{Participantes}

Participaram deste estudo 20 crianças, com idade média de 7,5 anos $(s d=0,71)$, homens e mulheres, alunos de escolas públicas e de uma instituição de educação complementar, de orientação religiosa ecumênica, na cidade de João Pessoa.

\section{Instrumentos}

Foi utilizado O Dilema de João. Tratava-se de uma entrevista semiestruturada, com 12 questões, referentes à estória de um menino chamado Joãozinho, uma adaptação, para crianças do Dilema de Heinz, um dilema moral utilizado por Enright em seus estudos com adolescentes e adultos (Enright, Santos \& Al-Mabuk, 1989). Nesta adaptação, Joãozinho descobriu que sua mãe tinha uma doença grave e necessitava de um remédio muito raro e caro. Somente um farmacêutico fabricava e vendia tal medicação. Sem condições financeiras para comprar a medicação, Joãozinho tentou comprar por um valor menor e parcelar o restante da dívida, porém o farmacêutico rejeitou tal proposta. Não havendo tempo nem condições de reunir todo o montante necessário, sua mãe não resistiu e morreu.

Este dilema foi representado em um livro de gravuras. Em seguida à estória, 12 questões foram apresentadas com o objetivo de avaliar: a capacidade de role-taking das crianças, ou seja, se elas conseguiam se colocar no lugar do personagem (Se você fosse Joãozinho como você se sentiria com tudo isso que aconteceu? Por quê?); o entendimento sobre o perdão (O que é perdoar?); as condições necessárias para que o perdão ocorra (Se o farmacêutico ficasse arrependido do que fez a Joãozinho e lhe 
desse muito dinheiro, você acha que isso ajudaria Joãozinho a perdoar o farmacêutico? Sim ou Não? Por quê? Se o farmacêutico pedisse desculpas, você acha que Joãozinho poderia perdoar o que ele fez? etc.); o grau de raiva (Quanta raiva Joãozinho sentiu quando o farmacêutico não quis lhe vender o remédio mais barato?) e o grau de perdão (Agora, imagine que você é Joãozinho, e responda: se você fosse Joãozinho, quanto que você perdoaria o farmacêutico?). As medidas de raiva e perdão foram representadas graficamente. No caso da raiva, existia uma ilustração, com uma sequência de três quadrados, organizados em tamanho crescente, de acordo com o grau de intensidade da raiva. A partir desta representação, a criança devia apontar qual o grau de raiva que ela sentiria se vivenciasse a situação da personagem do dilema. O quadrado menor representava "pouca raiva", o quadrado intermediário representava "alguma raiva" e o quadrado maior representava "muita raiva". No tocante à medida de perdão, ao serem questionadas sobre a possibilidade de Joãozinho perdoar o farmacêutico, as crianças poderiam optar por "não perdoar" ou por perdoar, em um dos três níveis representados nos quadrados. O quadrado menor significava "pouco perdão", o quadrado médio representava "mais ou menos perdão", e o maior quadrado significava "perdoar completamente".

\section{Procedimentos}

Este estudo foi primeiramente submetido às normas do Comitê de Ética em Pesquisa da Universidade Federal da Paraíba, recebendo autorização para ser realizado. Primeiro se estabeleceu contato com a instituição onde se realizariam as entrevistas. Segundo, foi feita uma reunião com os pais das crianças, a fim de explicar os objetivos do estudo, prestar esclarecimentos e obter o seu consentimento para a participação dos filhos. Nesta reunião, foi informado que as crianças poderiam decidir não participar ou interromper a participação na entrevista, sem nenhum tipo de prejuízo ou punição para elas.

Procedimentos para a entrevista: as crianças foram entrevistadas verbalmente e individualmente, em uma sala isolada da instituição de ensino. Cada entrevista teve uma duração aproximada de 20 minutos. Todas as entrevistas foram gravadas e posteriormente transcritas, para facilitar a análise dos dados. Apresentou-se a história por meio do livro de gravuras, em uma velocidade moderada, para que as crianças acompanhassem o ritmo dos acontecimentos. Após o fim da história, iniciou-se o questionário semiestruturado.

Procedimentos para a análise e a apresentação dos resultados: foram efetuadas análises de conteúdo das respostas e os resultados foram organizados na seguinte ordem de apresentação: capacidade empática, grau de raiva, entendimento do perdão, grau de perdão, relação entre raiva e perdão e condições para o perdão. Também foram efetuados levantamentos de frequências dos graus de raiva e de perdão.

\section{Resultados}

A análise de conteúdo mostrou que, quando questionadas sobre como se sentiriam se estivessem no lugar de Joãozinho, todas as crianças (100\%) responderam que sentiriam tristeza e raiva, demonstrando a capacidade de role-taking. No tocante ao grau de raiva, $81 \%$ delas escolheram muita raiva e $19 \%$ escolheram pouca raiva. Exemplos de verbalizações das crianças são:

- "triste, porque eu queria o bem de minha mãe" (A. O., menina, 7 anos);

- "triste, porque quando a pessoa morre, as famílias ficam muito tristes" (G. O., menina, 8 anos);

- "en ia ficar triste, porque ela é minha mãe e en gosto dela" (M. V., menina, 7 anos);

- "porque era para ele [o farmacêutico] ter dado o remédio... por isso en escolbi muita raiva" (G. O., menina, 8 anos);

- "porque ele é muito egoísta e não quis vender o remédio pela metade" (N. C., menino, 7 anos);

- "porque ele nunca queria ficar com o dinbeiro, enquanto eu juntava mais para comprar remédio" (M. V., menina, 7 anos).

Quanto à definição do perdão, 60\% das crianças não souberam definir, nem puderam decidir se o personagem central (Joãozinho) deveria perdoar ou não o personagem que o magoou (farmacêutico). A partir deste ponto, a entrevista deveria seguir para verificar as condições pelas quais o perdão pode ser oferecido. Porém, essa parte foi bastante prejudicada 
nesse grupo de crianças, que não mostrou uma compreensão conceitual sobre o que seja perdoar. Após cada pergunta, muitas crianças ficaram apenas repetindo o refrão "não sei". Assim, foram consideradas para análises apenas $40 \%$ dos participantes que apresentaram uma noção conceitual de perdão.

Dentre os $40 \%$ das crianças que apresentaram uma noção de perdão, verificou-se que a atitude de perdoar se pautava pela reconciliação e pelo restabelecimento das relações com quem magoou. Essa reconciliação se expressava por meio de "voltar a brincar", "pedir desculpas", "dar um abraço", entre outras ações. Exemplos disso são os seguintes relatos: "se abraça, dá um beijo... volta a brincar" (M. V., menino, 8 anos); "É quando a pessoa briga, faz besteira, pede desculpa, se abraça, pede desculpa, dá um beijo" (M. V., menina, 7 anos).

Quanto ao grau de perdão das crianças que demonstraram entendimento do conceito, 20\% das crianças escolheram a opção perdoarpouco, 15\% optaram por perdoar completamente e apenas uma criança $(5 \%)$ decidiu que o Joãozinho não deveria perdoar o farmacêutico.

A relação entre a raiva e o perdão foi encontrada nas verbalizações das crianças de duas formas. Na primeira delas, o perdão podia ocorrer como uma alternativa para combater a raiva: "Quando é a hora de parar de ficar com raiva, aí pede perdão" (R. E., menino, 7 anos). Na segunda forma, o perdão podia acontecer como uma consequência da diminuição da raiva. Para esta mudança ocorrer, as crianças se referiram à passagem do tempo como uma condição importante. Como exemplos, podem ser citados os seguintes relatos: "Com o passar os dias, a raiva dele vai abaixando e abaixando mais, ai ele [Joãozinho] perdoon ele [o farmacêutico]" (A. O., menina, 7 anos); "Vai passando os tempos, aí ele perdoa" (A. O., menina, 7 anos).

No tocante às condições para o perdão, as crianças indicaram quatro condições:

1) Pedido de desculpas, como condição importante para perdoar outra pessoa e reconciliar: "minha amiga brigou comigo, [...] no outro dia ela veio me pedir desculpa, ai eu pensei se desculpava ela ou não. Aí eu desculpei. Quando alguém briga ou faz alguma coisa de ruim, tem que pensar duas vezes antes de perdoar [...] porque o certo é isso" (G. O., menina, 8 anos);
2) Reparação e compensação: "Perdoava. Se o farmacêutico deu muito dinheiro, aíJoãozinho levou o dinheiropara casa, ficou metade com ele e muito com o pai dele, Joãozinho compraria muitas coisas" (R. B., menino, 7 anos);

3) Influência dos amigos para perdoar (expectativa social): "en faz̧ia uma votação com meus amigos. Se a maioria escolbesse perdoar, eu perdoava" (N. C., menino, 8 anos); "Perdoava ... os amigos são tudo para ele, brincam, se divertem, e quando a gente precisa de conselho, só tem os amigos para ajudar' (M. V., menina, 7 anos);

4) Expectativa religiosa e convenções sociais: "A palavra de Deus é muito honesta" (M. V., menina. 7 anos); "porque Deus perdoa todo mundo. E todo mundo tem que perdoarospróximos" (T.I., menina, 7 anos).

\section{Discussáo}

Considerando a literatura especializada sobre o perdão interpessoal em crianças, Piaget ([1932] 1994) e Enright, Santos e Al-Mabuk (1989) defendem a necessidade de role-taking para o perdão na perspectiva das vítimas. Nesse sentido, os resultados deste estudo indicam que as crianças foram capazes de exercer o role-taking, ao se colocarem no lugar da personagem, demonstrando sentimentos de raiva e tristeza. É possível afirmar, também, que a passagem do tempo, que era concebida como uma condição para o perdão em adultos, foi verificada como uma das condições necessárias para a diminuição da raiva e para que o perdão pudesse ocorrer. Nestes aspectos, as crianças que possuíam o conceito de perdão atenderam às expectativas teóricas criadas para adolescentes e adultos. Porém, os resultados também mostraram que nem todas as crianças que possuíam a capacidade de role-taking definiram o perdão e, entre aquelas que definiram, nem todas escolheram perdoar ou perdoar completamente. Esses resultados revelam que, desde cedo, ser capaz de adotar a perspectiva do outro não implica conhecer as formas de solução dos dilemas pela justiça ou pelo perdão, e mesmo entre os que já concebem o perdão e mostram-se capazes de se colocarem no lugar do outro, isso não implica necessariamente perdoar. Enright defende o perdão como uma escolha voluntária e autônoma. Aparentemente, essa lógica se aplica desde os 6 anos, 
no sentido de que conhecer não significa escolher. Porém, essa escolha pode estar presa a níveis de compreensão sobre os valores da justiça e do perdão.

No tocante às condições para que o perdão seja oferecido, as crianças demonstraram a necessidade de reparação e compensação, tal como era esperado. Porém, a maior ênfase foi dada na necessidade do pedido de desculpas, para perdoar. Tentando compreender a ênfase das crianças nesse aspecto, é possível interpretar que elas consideram o pedido de desculpas como uma reparação de caráter moral, aceita quando as consequências da mágoa causada não podem mais ser reparadas materialmente. Como no Dilema de João, no qual, para algumas crianças, a morte da mãe de Joãozinho não poderia ter uma reparação material equivalente, talvez elas tendam a considerar o pedido de desculpas do farmacêutico como uma indicação de caráter, demonstrando arrependimento e tentando reparar a mágoa.

Em seguida, os resultados demonstraram uma ênfase na "volta do brincar", como expressão da reconciliação. É preciso fazer um destaque sobre esta relação, estabelecida pelas crianças entre o perdão e a reconciliação. De acordo com a teoria de Enright et al. (1991), a reconciliação não estaria necessariamente relacionada ao perdão. Porém, o que se evidenciou nas respostas das crianças é que a reconciliação aparece como uma representação objetiva do conceito de perdão. De acordo com Piaget, as crianças desta faixa etária se encontram no período das operações concretas e têm dificuldade em analisar situações subjetivas. Por isso, a reconciliação pode estar servindo no âmbito comportamental o aspecto concreto do ato de perdoar, as crianças se utilizam desta ação concreta, por meio do "voltar a brincar", para dar significado à sua escolha de perdoar alguém. Provavelmente, por esta mesma razão, o pedido de desculpas surgiu como a condição de maior influência para a decisão de perdoar, já que representa, de maneira concreta, a intenção da outra parte em restabelecer os vínculos. Ainda considerando a divisão elaborada por Piaget para a evolução do julgamento moral, as análises das respostas indicam que as crianças deste estudo ainda utilizam o julgamento prático, ou seja, a moral objetiva, para avaliar as ações apresentadas no dilema.

Segundo o modelo de pensamento moral do perdão (Enright, Santos \& Al-Mabuk, 1989), as expectativas sociais e institucionais deveriam aparecer na adolescência. Entretanto, os resultados mostraram que as crianças já revelam um entendimento dessas condições. Talvez superficialmente e modelado por pressões no meio ambiente. Neste sentido, merece destaque a resposta que diz "eu faz̧ia uma votação com meus amigos. Se a maioria escolhesse perdoar, en perdoava" (N. C., menino, 8 anos), indicando um raciocínio de valorização das associações, de grupo de iguais, típico de pré-adolescentes e de uma moral heterônoma. Porém, essa valorização se desenvolve e deve aparecer, em sua forma autônoma, quando a pessoa compreende a importância política das associações. Assim, esses resultados indicam que, desde a infância, as considerações pelo perdão recebem a influência do pensamento político.

Considerando que o Brasil ainda não apresenta estudos sobre o pensamento do perdão em crianças, os resultados do presente estudo podem ser encarados como constituindo uma condição inicial para a preparação de currículos e programas de educação moral para o perdão nas escolas. Apesar de apresentar um cunho qualitativo e exploratório, espera-se que este estudo possa se revestir de um caráter inaugural, no sentido de favorecer o estabelecimento de programas educacionais voltados para o desenvolvimento moral e o perdão, além de contribuir para o aumento das pesquisas na área.

\section{Referências}

Al-Mabuk, R., Enright, R. D., \& Cardis, P. (1995). Forgiveness education with parentally love-deprived college students. Journal of Moral Education, 24, 427-444.

Camino, C., Camino, L., \& Leyens, J. P. (1996). Julgamento moral, emoção e empatia. In Z. A. Trindade \& C. Camino (Org.). Coletâneas da ANPEPP: Cognição Social e Juízo Moral (Vol. 1, n. 6, pp. 109-135) Rio de Janeiro: ANPEPP.

Denham, S. A., Neal, K., Wilson, B. J., Pickering, S., \& Boyatzis, C. J. (2005). Emotional development and forgiveness in children: Emerging evidence. In E. Worthington Jr. (Org.). Handbook of forgiveness (Cap. 9, pp. 127-142). New York: Routledge.

Enright, R. D., \& Fitzgibbons, R. P. (2000). Helping clients forgive. An empirical guide for resolving anger and restoring hope. Washington, DC: APA. 
Enright, R. D., Freedman, S., \& Rique, J. (1998). The psychology of interpersonal forgiveness. In R. D. Enright and J. North (Ed.). Exploring forgiveness. Madison, WI: University of Wisconsin Press.

Enright, R. D., Santos, M. J. D., \& Al-MAbuk, R. (1989). The adolescent as forgiver. Journal of Adolescence, 12, 95-110.

Enright, R. D., \& The Human Development Study Group (1991). The moral development of forgiveness. In W. M. Kurtiness \& J. L. Gewirtz (Ed.). Handbook of moral behavior and development (Vol. I, pp. 11-124). Hillsdale, NY: Erlbaum.

Freedman, S. R., \& Enright, R. D. (1996). Forgiveness as an intervention goal with incest survivors. Journal of Consulting and Clinical Psychology, 64(5), 983-992.

Gambarro, M. E., Enright, R. D., Baskin, T. W., \& Klatt, J. (2008). Can school-based forgiveness counseling improve conduct and academic achievement in academically at risk adolescents? Journal of Research in Education (in press).

Hepp-Dax, S. H. (1996). Forgiveness as an educational goal with fifth-grade inner city children. Unpublished doctoral dissertation, Fordham University.

Holter, A. C., Magnuson, C. M., Knutson, C., KnutsonEnright, J., \& Enright, R. D. (2008). The forgiving child: the impact of forgiveness education on excessive anger for elementary-aged children in milwaukee's central city. Journal of Research in Education (in press).

Kohlberg, L. (1984). Essays in moral development: (Vol. II) The psychology of moral development. Moral stages, their nature and validity. San Francisco: Harper \& Row.

Piaget, J. (1994). O juízo moral na criança. São Paulo: Summus. (Publicado originalmente em 1932).

Reed, G. \& Enright, R. D. (2006). The effects of forgiveness therapy on depression, anxiety, and post-traumatic stress for women after spousal emotional abuse. Journal of Consulting and Clinical Psychology, 74, 920-929.

Rodrigues, A. (1991). Psicologia social. Petrópolis: Vozes.
Selman, R. L. (1980). The growth of interpersonal understanding: Developmental and clinical analysis. New York: Academic Press.

Yeates, K. O., \& Selman, R. L. (1989). Social competencies in the schools: Toward an integrative developmental model for intervention. Developmental Review, 9, 64-100.

Yandell, K. (1998). The metaphysics and morality of forgiveness. In R. D. Enright \& J. North (Ed.). Exploring forgiveness (pp. 150-161). Madison, WI: University of Wisconsin Press.

Wade, N. G., Bailey, D. C., \& Shaffer, P. (2005). Helping clients heal: Does forgiveness make difference? Professional Psychology: Research and Practice, 36(6), 634-641.

Recebido: 27/04/2010

Received: 04/27/2010

Aprovado: 17/11/2010

Approved: 11/17/2010 